\title{
The Path of Motivated Blame and the Complexities of Intent
}

\author{
Janice Nadler \\ American Bar Foundation, Chicago, Illinois and Northwestern University School of Law, Chicago, Illinois
}

\section{Introduction}

In their article, Malle, Gugliemo, and Monroe (this issue) present their ambitious Path Model of Blame, which posits that blame judgments are processed according to a nested logic along particular paths. The authors make a strong case that their model can explain all instances of blame ranging over a wide variety of contexts, and in this sense it is a promising and powerful account of moral judgment. I also think the model has some limitations and areas where clarification is needed. The evidence and examples upon which the authors rely to illustrate their model are sometimes simplistic and not representative of several important types of blame situations that occur with frequency. Even relatively simple instances of blame, I argue, often necessitate breaking down an event into several acts and outcomes and identifying different mental states with respect to those events and outcomes that occur within the mind of a single actor. This more fine-grained analysis is necessary to illustrate how the Path Model of Blame operates according to its own terms and to reveal how the model needs to be extended and enriched to account for many everyday morally charged acts.

The nested logic by which the model specifies information processing in effect rules out the possibility of blame being distorted or motivated by beliefs and desires that do not directly bear upon the inputs specified in the model. In one sense, the Path Model of Blame represents a necessary corrective to prior work on blame that slips too easily into talk of bias, and I applaud this aspect. It is true that talk of exaggerated blame and the evaluative language of bias and distortion requires a normative baseline. Indeed, one cannot make the distinction between evidential and nonevidential factors without making normative choices about which factors should and should not influence blame. ${ }^{1}$ At the same time, I suggest that the authors have perhaps gone a bit too far in their effort to minimize or even banish the role of motivation in

\footnotetext{
${ }^{1}$ In fact, this is a fundamental basis of the law of evidence. The rules of evidence limit the information available to juries, despite its relevance, sometimes for policy reasons alone, and sometimes even just to advance goals unrelated to the case at hand. For example, rape shield laws exclude from evidence the sexual history of rape victims in order to encourage victims to come forward, and to avoid humiliating the victim (Bilz, 2010).
}

blame judgments, especially when motivation operates directly on the blame conclusion. As a general matter, my comments regarding the structure of the model and the role of motivation are designed to encourage further development of the Path Model of Blame, which does a great deal to clarify and frame the discussion of the processes underlying blame judgments.

\section{A Complete Model of Blame Must Account for Motivated Cognition}

Generally speaking, when decision makers have a preference regarding a conclusion or an outcome, they sometimes assess, construct, and evaluate their beliefs in such a way as to confirm that preference (Kunda, 1990). The fact that people sometimes evaluate preference-inconsistent information more critically than preference-consistent information is well established (Babcock, 1995; Babcock, Loewenstein, \& Issacharoff, 1997; Carlson \& Edward, 2001; Ditto \& Lopez, 1992; Kunda, 1987; Simon, 2004; Uhlmann, Pizarro, Tannenbaum, \& Ditto, 2009). Examples abound. Cherished beliefs (such as opposition or support for capital punishment) drive people's evaluations of the validity of scientific research that confirms or disconfirms the validity of those cherished beliefs (Lord, Ross, \& Lepper, 1979). People told that they test positively for a risk factor for a disease respond by increasing their estimates of the false positive rate and minimizing their perceptions of the seriousness of the disease (Ditto, Jemmott, \& Darley, 1988). People offered a cash incentive to accurately predict a judge's monetary award are less accurate when they have already been assigned the role of plaintiff or defendant in a mock settlement, compared to when they have not yet been assigned (Babcock, 1995).

It would be surprising if motivated cognition would, on one hand, influence judgments across such a wide variety of domains but, on the other hand, never influence judgments of blame. Malle et al., however, deny the possibility that blame judgments can be motivated by initial preferences or beliefs, without those preferences or beliefs first influencing the inputs in the Path Model (event detection, intent, reasons, capacity, obligation). We cannot have initial 
preferences about blame, they argue, because blame judgments can be reached only after considering event detection, causation, intent, and reasons. If an observer has a preference about blame, then according to the Path Model it is because, by definition, that observer has already taken into account the relevant inputs of causation, intent, and reasons. Thus, although people try to preserve their cherished beliefs about politics, their health, and the like, the blaming process is a sealed system and any inputs must be perceived as relating to event detection, causation, intent, or reasons.

It may be helpful at this juncture to separate the notion of motivation, on one hand, and bias, on the other. For purposes of this discussion, I define motivated cognition generally as occurring when an individual's preference for a particular outcome or conclusion influences his or her assessment of facts and evidence supporting the preferred outcome or conclusion. This process might or might be justified on a normative account of reasoning. Bias, on the other hand, implies a departure from a normative account of information processing. Let us put aside for the moment questions of bias and focus only on whether a complete model of psychological blame should include the possibility of motivated cognition. Is there evidence that motivated cognition plays a role in judgments related to blame? If so, how well does the Path Model account for the role of motivated cognition?

\section{Interpreting Blame for Unintended Outcomes}

In one experiment based on a real incident (State $v$. Davidson, 1999), a woman's dogs escaped from her fenced yard while she was sleeping and mauled a child to death (Nadler \& McDonnell, 2012). Participants blamed the woman (Sara) less for the child's death when she was described as generally being sociable, generous, and having a healthy lifestyle, compared to when she was described as being asocial, ungenerous, and having an unhealthy lifestyle. Is this an example of motivated cognition? According to a motivated cognition account, participants had a preferred conclusion-increased blame-which they rationalized by perceiving Bad Sara as having acted more intentionally with regard to the child's death than Good Sara. Thus, perceivers learned Sara's bad traits and were motivated to blame her more because she is a bad person, and rationalized this blame by processing the information about intent so as to support this blame preference. Indeed, Bad Sara was perceived as having acted more intentionally toward the child's death than Good Sara.

Another way to interpret these results is that Bad Sara's characteristics (asociality, ungenerosity, unhealthy lifestyle of smoking, junk food, and no exercise) gave rise to the inferences of increased inte- nt, without having to posit any initial preference for increased blame. That is, according to the Path Model, perceivers could reasonably infer that compared to Good Sara, Bad Sara cared less about whether her dogs were properly secured and whether they posed a danger to other people. Bad Sara, through her asociality, ungenerosity, and unhealthiness, was more likely than Good Sara to be the kind of person who has an indifferent attitude toward the well-being of others. Thus, according to the Path Model of Blame, it is quite possible that perceivers saw Bad Sara as having acted in a more intentional fashion with respect to the child's death, and perceivers' blame judgments flow directly from these inputs specified by the model rather than for a preference for more severe blame.

In another experiment based upon a real incident (People v. Hall, 2000), participants read about an out-of-control skier (Nathan) who crashed into another skier below, resulting the death of the other skier (Nadler, 2012). Nathan was described either as a model employee, an animal shelter volunteer, and helpful to his family's small business (hereinafter "Good Nathan") or as an unreliable employee, rarely helping his family, and spending his free timing relaxing ("Bad Nathan"). As in the dog experiment, participants who read about Bad Nathan blamed him more for the death than those who read about Good Nathan. Bad Nathan was perceived as more intentional toward the death of the skier than Good Nathan. The motivated cognition interpretation of these results is that participants who read about Bad Nathan preferred harsher blame and were motivated to perceive his actions as more intentional to justify preference for increased blame. Another interpretation is that participants who read about Bad Nathan perceived his state of mind as more indifferent toward the well-being of other skiers in his path compared to Good Nathan. As a result, he was perceived as acting more intentionally toward the other skier's death, and as predicted by the Path Model of Blame, they blamed Bad Nathan more severely than Good Nathan.

In a follow-up experiment, Nathan's character was manipulated within subjects (Nadler, 2012). That is, each individual participant read about and rated the blame of both Good Nathan and Bad Nathan. The order of presentation of Good and Bad Nathan was counterbalanced. The difference in blame judgments between Good and Bad Nathan disappeared when the same participant read about both versions of Nathan. Participants reading the second version of the story adjusted their blameworthiness judgments, as well as their judgments of intent, to essentially match their ratings in the first version of the story. This suggests that when Nathan's moral character was made salient as an input into the blame judgment, participants rejected it as a legitimate basis for blame. 
This seems inconsistent with the Path Model of Blame. If Nathan's moral character is perceived as a relevant piece of information for judgments about intent, then participants should take moral character into account when judging intent regardless of whether they hear about only one version of Nathan or both. Similarly, if Nathan's moral character is perceived to be undiagnostic of intent, then participants should not take moral character into account when judging intent, regardless of hearing about only one version of Nathan or both. Notice that we do not need to make any assumptions here about whether participants are making an error or are biased when they are influenced by moral character-in fact, strong philosophical arguments can be made for both positions (Bayles, 1982; Huigens, 1995; Pizarro \& Tannenbaum, 2012; Sendor, 1996). The important point here is that when confronted with both versions of Nathan's moral character, participants' judgments indicate that they do not think character should influence blame in this particular case.

Malle et al.'s (this issue) interpretation of the within-subjects version of the experiment is different. They argue that "people can better distinguish between causally relevant and irrelevant factors in a within-subject design. When two agents with very different character cause identical outcomes, then character is unlikely to be the relevant cause" (p. 163). Thus, participants in the within-subjects version of the experiment perceive that moral character is irrelevant to blame, whereas subjects in the between-subjects experiment fail to perceive the moral-irrelevance of blame. Malle et al. imply that in the between-subjects version, participants are dutifully using all the information given to them, and the fact that moral character influences blame is merely a demand characteristic: Participants take character into account because they assume the experimenter wants them to take it into account. Otherwise, according to Gricean maxim of relevance (Grice, 1975), the experimenter would not have included the moral character information at all.

On this account, the inclusion of moral character information in the within-subjects version of the experiment does not follow the relevance maximthat is, the participants now no longer infer that moral character is relevant. But why not? If participants inferred that the experimenter wanted them to consider moral character in reading one version of the story, why wouldn't participants similarly infer the same thing in the within-subjects version of the experiment? It is difficult for the Path Model to reconcile the within-subjects participants deciding to disregard character in their blame judgments when the between-subjects participants were influenced by it-in both versions according to the Path Model, character would influence intent (or in both character would not influence intent). On the other hand, motivated cognition often operates within an illusion of objectivity: People are unaware that their blame judgments are based upon a factor like character or likeability that might seem irrelevant; when that factor is made salient, they adjust their blame judgment to ensure it is not influenced by this factor and to maintain the illusion of objectivity.

\section{Interpreting Blame When Harm Is Required}

Whether the Path Model can account for the role of moral character for unintended outcomes in the two experiments just described is, admittedly, unclear. There are other experiments, however, that provide stronger support for the notion of motivated moral judgment as Malle et al. define it, demonstrating observers using information with no diagnostic value for the blame judgment at issue. Consider, for example, Sood and Darley's (2012, Experiment 2) study of the motivated recruitment of harm, in which they identified a situation - a man going to the supermarket in the nude- that most pilot-test respondents said did not cause harm but that many think should be criminalized. In the experiment, half the participants were told that a criminal penalty can be imposed only on conduct that is shown to cause harm (harm constraint condition), and half were not given this instruction (control condition). Harm was defined as "injury to a person or persons that can be clearly demonstrated." The percentage of participants who thought nude shopping should be punished did not differ across conditions. But participants in the harm constraint condition were motivated to find the conduct harmful-they were more than twice as likely as control participants to perceive that nude shopping caused harm. ${ }^{2}$ Those who wanted to punish the conduct were not only much more likely to perceive the existence of harm but also more likely to perceive greater harm magnitude when harm was a requirement of penalization, as compared to when no constraint was imposed on criminalization.

The motivated moral cognition interpretation of the results of this experiment is that participants in the harm constraint condition who were motivated to punish nude shopping used the nondiagnostic fact of the harm constraint to perceive harm; those in the control condition had no such constraint and were not as inclined to perceive harm in order to fulfill their goal of criminalization. But another interpretation is possible: that in the harm constraint condition participants simply paid more attention to harm, performing a "more intense but essentially objective search" (Kunda, 1990, p. 489). To rule out this possibility, in

\footnotetext{
${ }^{2}$ In this experiment a similar pattern was found for the act of defiling a national flag.
} 
another experiment Sood and Darley (2012, Experiment 3) examined whether the actor's ideologically repugnant viewpoint would motivate the finding of harm. Participants were categorized as holding a prolife or pro-choice attitude on abortion. ${ }^{3}$ All participants were instructed that public nudity cannot be criminalized unless it causes harm. Half were presented with a scenario in which a nudist in a supermarket held up a sign and handed out fliers stating why abortion should be legalized; for the other half, the sign and fliers stated why abortion should not be legalized. Thus, the nudist's message was either congruent or incongruent with each participant's own ideological position.

Consistent with motivated moral cognition, participants judging a nudist with an ideologically incongruent position imposed more severe punishment ${ }^{4}$ than participants judging an ideologically congruent nudist. Participants also imputed more harm to the nudist's conduct if the nudist's message was incongruent than if it was congruent with the participant's own attitude. This harm plasticity effect emerged among both pro-life and pro-choice participants. The ideological position is undiagnostic of criminal punishment because it is not only legally irrelevant but also unconstitutionally impermissible to consider under the First Amendment. Arguably then, the nudist's ideological position is also undiagnostic of blame in this context.

One interpretation of these results is that pro-life participants believe that real harm comes from publicly advocating a pro-choice position, whereas no harm comes from advocating a pro-life position, and that pro-choice participants believe the converse. Thus, despite the fact that the nudist's ideological message was legally undiagnostic of blame, participants found it to be intuitively diagnostic of harm and therefore blame. On this view, the results illustrate not motivated moral reasoning but rather ordinary blame judgment fully explained by the Path Model. There are two difficulties with this interpretation. First, according to the Path Model account, it was the participants' perception of the nudist's ideology, rather than the nudity itself, that caused them to perceive blame and therefore impose more severe punishment. But this is not what participants report having done. When participants were asked to describe the harm they perceived in the scenario, they focused exclusively on public nudity and not on the nudist's position on abortion. ${ }^{5}$ It seems unlikely, then, that in the event detection stage participants perceived extra harm from the incongruent message,

\footnotetext{
${ }^{3}$ Those with moderate views were excluded from the analysis.

${ }^{4}$ In the form of more prison time and a higher fine.

${ }^{5}$ Only one participant out of a total of 53 mentioned the nudist's position on abortion in their description of harm.
}

eventually leading to great blame and punishment. What seems more likely is that the incongruent message gave rise to an impulse to perceive increased blame and to enhance punishment, and participants indicated increased harm as a way to justify doing so. Disagreement with the nudist's message on abortion increased motivations to blame, leading to more severe punishment and correspondingly an increased recruitment of harm to justify punishment.

There is a second difficulty in accounting for these results within the confines of the Path Model of Blame. In a follow-up study, Sood and Darley (2012, Experiment 4), used a within-subjects design and found that when each participant was asked to rate the nudist's conduct in both the congruent and incongruent conditions, there were no differences in mean punishment severity and no differences in mean perceived harm. It appears that being exposed to both the incongruent and congruent scenarios reduced the likelihood that participants would recruit the nondiagnostic fact of the nudist's ideological position to gauge punishment and harm. When the ideological motive for punishment was made transparent, the illusion of objectivity was shattered, and participants no longer used it for their judgments of punishment.

Other studies within legal contexts have found similar results regarding the motivated perception of harm in service of blame judgments. For example, Kahan, Hoffman, Braman, Evans, and Rachlinski (2012) measured participants' ideology with regard to their cultural commitments, categorizing participants on two dimensions according to their orientation on scales of individualism versus communitarianism and hierarchy versus egalitarianism. Participants watched a video of a political demonstration. Half believed that the demonstrators were protesting abortion outside of an abortion clinic, and the other half believed that the demonstrators were protesting the military's policy of discrimination against gays outside of a military recruitment center. In First Amendment law, unruly speech is protected, but unruly conduct is not. Participants were asked whether the protestors had crossed the line from speech to illegal conduct, in the form of obstructing, spitting at, shoving, or touching individuals seeking to enter the building. Participants holding opposing cultural positions (e.g., Hierarchical Communitarians v. Egalitarian Individualists) substantially disagreed about whether the protestors engaged in illegal conduct. For example, Egalitarian Individualists were more likely to report seeing illegal conduct by the antiabortion protestors than Hierarchical Communitarians (and vice versa for the anti-gay-discrimination protestors). Analogously, participants with the same cultural positions but who saw "different" protests also substantially disagreed about whether the protestors engaged in illegal conduct. For example, 
Egalitarian Individualists watching the same video reported seeing more illegal conduct if they thought they were watching an antiabortion protest compared to an anti-gay-discrimination protest. The same patterns emerged with respect to blame-related judgments of whether the protestors were violating the law, and whether the police should pay damages for interfering with the protests.

Analogous culturally motivated judgments of fact have been found in numerous other studies (Kahan, 2010; Kahan \& Braman, 2008; Kahan, Braman, Gastil, Slovic, \& Mertz, 2007). The Path Model of Blame does not account well for these findings. We do not need to posit exaggerated blame, distortion, bias, or error in these findings to see that they demonstrate that the process of forming judgments of blame is sometimes more complex than predicted by the Path Model. People's desire to blame the nudist in the grocery story causes them to perceive harm, but only when harm is required for punishment and not when it is not required. The Path Model's closed system of linear reasoning cannot explain this well. The first stage of the model, Event Detection, is described as a simple process that involves little more than evaluating an event as bad (p. 17). Yet Sood and Darley (2012, Experiment 2) appear to demonstrate that perception of harm during event detection can be influenced by desire to punish. To the extent that desire to punish is related to desire to blame, to account for this a model of blame would need to have a causal arrow that runs from blame to event detection.

Similarly, people's desire to punish both the nudist (Sood \& Darley, 2012, Experiment 3) and the protestors (Kahan et al., 2012) expressing repugnant ideological views prompted them to identify harm. A defender of the Path Model might argue that the model can account for this by simply positing that Event Detection can be influenced by any number of factors, including ideology. But this defense assumes a lock-step causal sequence of perceiver's ideology $\rightarrow$ event detection/harm perception $\rightarrow$ blame, which is a sequence that is at odds with the fact that perceivers are motivated to see harm when blame requires it, and less so when blame does not require a finding of harm (Sood \& Darley, 2012, Experiment 2).

Moreover, the phenomenon of motivated detection of whatever facts are necessary to justify blame recently has been replicated in a different context. Sood (2014) presented participants with a scenario involving police illegally searching a car and finding contraband. In one version the driver had heroin that he was selling to high school students; in another version the driver had marijuana that he was selling to terminally ill cancer patients. All participants learned that the exclusionary rule requires that evidence obtained through an illegal police search is excluded in criminal cases, regardless of the seriousness of the underlying crime. The practical result of excluded evidence in contraband cases is that the defendant goes unblamed and unpunished by the legal system. But there is an exception to the exclusionary rule: If the contraband would have been inevitably discovered through legal means, then it is not excluded from evidence in court.

Participants in the heroin condition were more likely than those in the marijuana condition to decide that the drugs were admissible because their discovery was inevitable, thus clearing the way for the driver to be blamed and punished. These results are difficult to account for by the Path Model. Outside of the exclusionary rule context, the Path Model predicts event detection of greater harm for heroin compared to marijuana, and so greater blame and punishment. But it is unclear how the Path Model can explain the fact that participants were more likely to perceive inevitable discovery (which clears the way for blame and punishment) for heroin than for marijuana. Once again, it seems that the desire to blame and punish the more serious conduct of heroin sale to children motivates the finding of inevitable discovery, in order to then justify the more serious blame and punishment for heroin. To account for this, it seems that the model should include a causal arrow that runs from blame to event detection.

In sum, although Malle et al. (this issue) pay lip service to motivation in the introduction section of their article ("We should emphasize that this focus on concepts and information processing in no way denies the role of affect and emotion in blame or the possibility of motivated reasoning"; p. 150), it is a serious problem for the Path Model of Blame that it does not have a way of accounting for the reality that moral reasoning is sometimes (but not always) motivated. People have all sorts of reasons for wanting blame judgments to come out a certain way. When this is the case, some of the arrows in the model are reversed (or flow in both directions). Malle et al. strain to interpret all motivated blame as merely the attempt of "inferentially hyperactive" perceivers who "inspect any information they receive for signs of what they want to know: the agent's causal role, mental states, obligations, preventive actions" (p. 164). But in the incongruent ideology studies (Kahan et al., 2012; Sood \& Darley, 2012), participants were not using the actors' repugnant ideology as inputs for causal role, mental states, and so on. Rather, they were searching for ways to justify their motivation to blame and punish the actors more severely than they would in the congruent ideology condition. Thus, pro-choice participants decided that public nudity was more harmful when the actor's message was pro-life (Sood \& Darley, 2012) and were more likely to perceive conduct that 
did not in truth occur (shoving, blocking, and the like) when protestors' purpose was incongruent with their own cultural commitments (Kahan et al., 2012). Similarly, perceivers who were faced with the possibility of failing to punish a dangerous heroin pusher were more likely to say that discovery of the evidence was inevitable compared to those faced with punishing a relatively harmless medical marijuana peddler (Sood, 2014). In this way, perceivers were not so much "inspecting information they receive for signs of what they want to know" as they were manufacturing reasons to justify what they already decided about blame and punishment.

Note also that not all accounts of motivated moral reasoning predict that undiagnostic information "should influence all components of blame (e.g., bad character influencing perceived causality, intentionality, reasons, etc.)" (p. 164). Many researchers posit that motivated cognition operates under an illusion of objectivity to protect the integrity of the person making the judgment (Kunda, 1990). In this way, people often do not adjust their rationales more than what is needed to justify their desired conclusion. In deciding how severely to punish the nudist, those motivated by incongruent ideology needed only to recruit one factor to justify increased blame-the harm of nudity. Similarly, to punish the protestors, perceivers needed only to report seeing key actions (Kahan et al., 2012), and to punish the heroin pusher perceivers needed only to report inevitable discovery of the evidence (Sood, 2014). There was no need for them to inspect or be influenced in their perceptions of other factors, like causality, intentionality, or reasons, contrary to Malle et al.'s characterization of motivated moral cognition.

\section{Moral Agents Who Cause Events Often Act With Mixed Mental States}

"The Path Model's novel and unique claim is that intentionality judgments bifurcate the perceiver's information processing" (p. 154). By necessity then, perceivers must cleanly distinguish intentional from unintentional conduct. If conduct is perceived as intentional, perceivers consider the actor's reasons for engaging in the conduct. On the other hand, if conduct is perceived as unintentional, then perceivers consider the actors obligation and capacity to prevent the outcome. The authors allow that opposing information about intentionality might arise, in which case the perceiver steps back and updates the intentionality judgment and perhaps switches paths. But the main idea here is that there are two paths that lead to the processing of very different information.

I would like to suggest that intentional and nonintentional mental states are not always clearly dichotomous in the way represented by the model and claimed by the authors, and this might pose a problem for the extent to which the model is able to account for reasoning about blame. To be sure there are examples of purely intentional actions, such as purposely stealing a steak from a grocery store. Here we want to know the actor's reasons before arriving at a blame judgment, and the questions on the nonintentional branch of the model of obligation and capacity do not arise. Conversely, a driver who misjudges his ability to make it through an intersection prior to a red light and who accidentally hits a pedestrian is someone about whom we are mostly concerned with obligation and capacity to prevent the accident, and not so much with his reason for thinking he could make it through the light, assuming it was a lapse in judgment of distance and time.

But even accidents sometimes demand reasons, and the Path Model does not anticipate this. A driver who is texting and as a result accidentally kills a pedestrian might raise questions about the urgency of the texting: Was she engaged in casual conversation, or was she sending an urgent message? These are not questions about obligation and capacity on the nonintentional branch but rather questions about reasons on the intentional branch. As the act moves from purely unintentional (e.g., sneezing while driving) toward involving more intentional actions, the demand for reasons increases. Consider a driver who is speeding and kills a pedestrian as a result. The death was caused accidentally rather than intentionally-suppose the driver never even considered the possibility that someone might die as a result of how he was driving. But if the driver was a teenager who was speeding to try to show off for his friends in the car, we are likely to blame differently than if the driver was a father rushing his injured child to the hospital (Pillsbury, 2000). Thus, even for accidents we sometimes demand reasons before we can assess blame.

Many blame situations involve a mixture of intentional and unintentional actions. Consider a teenager playing "Russian Roulette" who intentionally points a gun at his friend and intentionally pulls the trigger (Commonwealth v. Malone, 1946). Unbeknownst to him there is a bullet in the chamber, and the friend is shot and killed, a result he completely fails to anticipate. Or consider a man who intentionally drinks so much alcohol that he is incapacitated almost to the point of unconsciousness, then gets in his car and unintentionally crosses several lanes into oncoming traffic, resulting in another driver's death (U.S. v. Fleming, 1984). In both of these examples, the initial conduct was intentional, but the resulting death was unintentional. The Path Model includes an input for intentionality, but the starkly bifurcated path between intentional and unintentional acts does not account 
for how perceivers might consider both the intentional and nonintentional aspects of the event. The teenager was obligated to and capable of not playing casually with a gun, but the reasons for his actions are explained by a tragic combination of immaturity and stupidity, which we need to consider in order to distinguish him from the adult killer for hire, whom we blame more severely. Similarly, we might decide that although obligated to not cross into oncoming traffic, the drunk driver was at the time incapable of avoiding this action, but his lack of capability warrants consideration of the reason, which is that he intentionally drank to the point of incapacitation.

The need to consider for certain nonintentional conduct the actor's reasons in conjunction with obligation and capacity emerges clearly in State v. Williams (1971), in which a 17-month-old baby died from a severe tooth infection. The parents, who were young, were inexperienced, and had very little education, did not realize how sick the baby was. Thus, although they were obligated to provide sufficient medical care to prevent the baby's death, it is not clear that they were capable of realizing the necessity of doing so. Besides not realizing the urgency of the situation, there was another factor that caused the parents to hesitate to seek medical attention: They were Shoshone Indians, and at the time (the 1960s), government social workers were removing more than $25 \%$ of Native American children from their homes and placing them with non-Native American foster parents. In fact, the father's cousin lost custody of her child that way. The parents were not only unaware of the urgency of their baby's condition but also afraid of being victims of the government's misguided social policy. Thus, even though the child's death was an accident, the consideration of reasons is an important aspect of assessing blame here. In sum, to account for the interdependence of reasons, obligations, and capacities, a revision of the model might be in order.

\section{Conclusion}

The Path Model predicts "that upon detecting a negative event, perceivers will first seek information about causality, then (if the event was agent-caused) about intentionality, then (if the event was intentional) about either reasons or (if the event was unintentional) about preventability" (p. 156). I think this is a good starting template, but not every blame judgment follows this path. Sometimes perceivers begin with a sense of blame, and work backward through the information provided to find the harm or other circumstance that justifies blame (Sood \& Darley, 2012; Sood, 2014). Given that motivated cognition is wellestablished in other areas of judgment, it would be astonishing if blame judgments were immune from this possibility. Thus, people are more likely to see harm in public nudity only when harm is a condition for blame (Sood \& Darley, 2012). But when people are confronted with a source of information that they themselves view as undiagnostic, such as in the within-subjects experiments, people adjust their blame judgments so they are not influenced by the undiagnostic information (Nadler, 2012; Sood \& Darley, 2012; Sood, 2014). The Path Model works well when explaining blame judgments for moral transgressions like "Eric broke Monica's arm" (p. 157) but less well when blame for moral transgressions is complicated by cultural commitments, ideology, character perceptions, or lack of concrete harm.

In addition, the bifurcation in the structure of the Path Model between intentional and nonintentional conduct should be revised in light of the complicated nature of the mental states and conduct underlying many kinds of moral transgressions. My bottom line, however, is that the Path Model represents a very promising starting point for modeling the psychology of blame judgments. It has captured the essential elements of blame judgments and distinguished them from other, previously identified elements which were duplicative, imprecise, or otherwise muddled. The model explains or is at least consistent with a great number of established findings in areas of moral judgment. Revisions to the model that reflect more complexity in the processes of information seeking and updating will result in a more accurate and powerful explanation of a wider variety of findings.

\section{Note}

Address correspondence to Janice Nadler, American Bar Foundation, 750 North Lakeshore Drive, Chicago, IL 60611. E-mail: jnadler@ northwestern.edu

\section{Funding}

This work was supported by the American Bar Foundation.

\section{References}

Babcock, L. (1995). Biased judgments of fairness in bargaining. American Economic Review, 85, 1337-1343.

Babcock, L., Loewenstein, G., \& Issacharoff, S. (1997). Creating convergence: Debiasing biased litigants. Law \& Social Inquiry, 22, 913-925.

Bayles, M. D. (1982). Character, purpose, and criminal responsibility. Law and Philosophy, 1, 5-20. 


\section{COMMENTARIES}

Bilz, K. (2010). We don't want to hear it: Psychology, literature and the narrative model of judging. University of Illinois Law Review, 2010, 429.

Carlson, K. A., \& Edward, J. (2001). Biased interpretation of evidence by mock jurors. Journal of Experimental Psychology: Applied, 7, 91-103.

Commonwealth v. Malone., 354 Pa. 180 (1946).

Ditto, P. H., Jemmott, J. B., \& Darley, J. M. (1988). Appraising the threat of illness: A mental representational approach. Health Psychology, 7, 183-201.

Ditto, P. H., \& Lopez, D. F. (1992). Motivated skepticism: Use of differential decision criteria for preferred and nonpreferred conclusions. Journal of Personality and Social Psychology, $63,568-584$.

Grice, H. P. (1975). Logic and conversation. Syntax and Semantics, 3, 41-58.

Huigens, K. (1995). Virtue and inculpation. Harvard Law Review, $108,1423$.

Kahan, D. M. (2010). Culture, cognition, and consent: Who perceives what, and why, in acquaintance-rape cases. University of Pennsylvania Law Review, 158, 729-813.

Kahan, D. M., \& Braman, D. (2008). The self-defensive cognition of self-defense. American Criminal Law Review, 45, 1.

Kahan, D. M., Braman, D., Gastil, J., Slovic, P., \& Mertz, C. K. (2007). Culture and identity-protective cognition: Explaining the White-male effect in risk perception. Journal of Empirical Legal Studies, 4, 465-505.

Kahan, D. M., Hoffman, D. A., Braman, D., Evans, D., \& Rachlinski, J. J. (2012). "They saw a protest": Cognitive illiberalism and the speech-conduct distinction. Stanford Law Review, 64, 851-906.

Kunda, Z. (1987). Motivated inference: Self-serving generation and evaluation of causal theories. Journal of Personality and Social Psychology, 53, 636-647.

Kunda, Z. (1990). The case for motivated reasoning. Psychological Bulletin, 108, 480-498.
Lord, C. G., Ross, L., \& Lepper, M. R. (1979). Biased assimilation and attitude polarization: The effects of prior theories on subsequently considered evidence. Journal of Personality and Social Psychology, 37, 2098-2109.

Nadler, J. (2012). Blaming as a social process: The influence of character and moral emotion on blame. Law \& Contemporary Problems, 75, 1-31.

Nadler, J., \& McDonnell, M.-H. (2012). Moral character, motive, and the psychology of blame. Cornell Law Review, 97, 257304.

People v. Hall, 999 P.2d 207 (2000).

Pillsbury, S. H. (2000). Judging evil: Rethinking the law of murder and manslaughter. New York, NY: NYU Press.

Pizarro, D. A., \& Tannenbaum, D. (2012). Bringing character back: How the motivation to evaluate character influences judgments of moral blame. In M. Mikulincer \& P. R. Shaver (Eds.), The social psychology of morality: Exploring the causes of good and evil (pp. 91-108). Washington, D.C.: American Psychological Association.

Sendor, B. B. (1996). The relevance of conduct and character to guilt and punishment. Notre Dame Journal of Law, Ethics \& Public Policy, 10, 99-136.

Simon, D. (2004). A third view of the black box: Cognitive coherence in legal decision making. University of Chicago Law Review, 71, 511-586.

Sood, A. M. (2014). Cognitive cleansing: A psychological perspective on the exclusionary rule. Unpublished manuscript.

Sood, A. M., \& Darley, J. M. (2012). Plasticity of harm in the service of criminalization goals. California Law Review, 100, 1313.

State v. Davidson, 267 Kan. 667 (1999).

State v. Williams, 4 Wash. App. 908 (1971).

Uhlmann, E. L., Pizarro, D. A., Tannenbaum, D., \& Ditto, P. H. (2009). The motivated use of moral principles. Judgment and Decision Making, 4, 476-491.

U.S. v. Fleming, 739 F.2d 945 (1984). 